\section{RSP}

http://www.rsp.fsp.usp.br/
Revista de Saúde Pública

\title{
Impact of oral condition on the quality of life of homeless people
}

\author{
Juliana Aparecida de Campos Lawder' (iD, Marcos André de Matos" (iD, João Batista de Souza' \\ Maria do Carmo Matias Freire' ${ }^{\mathrm{I}}$ (D) \\ ' Universidade Federal de Goiás. Faculdade de Odontologia. Programa de Pós-Graduação em Odontologia. \\ Goiânia, GO, Brasil \\ " Universidade Federal de Goiás. Faculdade de Enfermagem. Programa de Pós-Graduação em Enfermagem. \\ Goiânia, GO, Brasil
}

\begin{abstract}
OBJECTIVE: To describe the prevalence of oral health impact on quality of life and its association with the dental condition and sociodemographic factors of homeless people.

METHODS: The sample was composed of 116 adults, temporarily attended by a public institution in the municipality of Goiânia, state of Goiás. Interviews were carried out including the Oral Impact on Daily Performance instrument and sociodemographic aspects. Clinical examinations were done by a trained examiner considering criteria of the World Health Organization. We evaluated dental caries (DMFT index) and use or need to use some type of prosthesis. For the statistical analysis of data, we used Pearson's Chi-square and Fisher's exact tests and Poisson regression with robust variance.
\end{abstract}

RESULTS: Of the total respondents, $81.9 \%$ had at least one daily performance affected by dental problems in the six months prior the survey. The most prevalent dental conditions were: need for lower $\operatorname{arch}(76.7 \%$ ) and upper arch prosthesis (69.0\%); untreated caries (75.9\%); and high DMFT (57.8\%). In bivariate analysis, only the need for upper prosthesis variable was associated with the impact (high Oral Impact on Daily Performance). In the regression model, adjusted for time in the institution, age, and sex, this association remained significant $(p=0.015)$. Individuals without need for upper prosthesis had prevalence of high impact on daily performance $55 \%$ lower than those in need of this type of prosthesis $(\mathrm{p}=0.018)$.

CONCLUSIONS: The prevalence of oral health impact on quality of life of homeless people was high and higher than that verified in the overall Brazilian population. The impact was associated with the need for upper prosthesis, regardless of sociodemographic characteristics of the individuals.

DESCRIPTORS: Homeless Persons. Oral Health. Sickness Impact Profile. Health Vulnerability.

Quality of Life.

How to cite: Lawder JAC, Matos MA, Souza JB, Freire MCM. Impact of oral condition on the quality of life of homeless people. Rev Saude Publica. 2019;53:22.

Copyright: This is an open-access article distributed under the terms of the Creative Commons Attribution License, which permits unrestricted use, distribution, and reproduction in any medium, provided that the original author

and source are credited.

Maria do Carmo Matias Freire Faculdade de Odontologia

Setor Leste Universitário

74605-020 Goiânia, GO, Brasil

Received: Feb 1, 2018 


\section{INTRODUCTION}

Oral problems, particularly dental caries and its consequences, have high prevalence in the population and are related to pain, suffering, mutilation and privations ${ }^{1}$.

Studies that assess the perception of individuals on their oral conditions are an important contribution to the understanding of the social impact of diseases and other health outcomes ${ }^{2}$. Moreover, they may be relevant to support public policies seeking to establish priorities and reduce inequities and the impact of outcomes on people's quality of life. In this sense, several indicators aiming to integrate subjective measures into clinical data have been developed and validated ${ }^{3}$. The use of these indicators in the field of dental public health has been growing, but studies on vulnerable social groups are still incipient, in particular those on homeless people.

In Brazil, there are no conclusive studies on the profile and the number of people living in the streets; however, it is a growing, heterogeneous, and fluctuating social group, with difficulties of access to healthcare services ${ }^{4}$. Since they are socially excluded, they end up not being focus of healthcare initiatives and scientific research. Accordingly, strategies and actions aimed at improving healthcare initiatives for the population of homeless people have been proposed by the Brazilian Ministry of Health in the last years ${ }^{5,6}$.

In addition to the low priority given to this population, having no fixed location of permanence, the insecurity and the adverse psychic and physical conditions of these individuals are factors that hinder investigations comprising all methodological rigor advocated in the epidemiology field. The unique national survey on homeless people did not address specific questions about oral health, and this was not cited by the participants when reporting their major health problems ${ }^{4}$. However, for a group of homeless people interviewed in a qualitative research conducted in Salvador, state of Bahia, dental problems were among the major health problems faced ${ }^{7}$.

Studies on the impact of oral health on the quality of life of homeless people were conducted in Australia ${ }^{8}$, United States of America ${ }^{9}$, China ${ }^{10}$, and European countries ${ }^{11-13}$. Results demonstrated a precarious condition of oral health, with indexes higher than those verified in the general population, and which negatively impact on the quality of life of these individuals.

In Brazil, studies on the oral health of homeless people are scarce. A single study evaluated its impact on the quality of life, using descriptive approach and restricted to men of a municipality in the Southeast region, and showed high prevalence of self-reported morbidity and negative impact ${ }^{14}$.

Further investigations are necessary to elucidate the extent to which oral health negatively affects the life of homeless people in Brazil, which clinical conditions influence this impact, and which are other associated factors. Based on the unfavorable-life context of these individuals, we assume that caries and consequent edentulism negatively affect their daily performance. The findings may contribute to develop public policies aimed at this socially marginalized group, but which has the right to oral health with quality of life.

Our study aimed to describe the prevalence of oral health impact on quality of life and its association with the dental condition and sociodemographic factors of homeless people.

\section{METHODS}

Cross-sectional study, conducted at Casa de Passagem (Temporary Shelter), the only municipal public institution that temporarily houses homeless people in the municipality of Goiânia, state of Goiás, Brazil. This research is part of a wider project entitled "Avaliação da situação de saúde da população em situação de rua de Goiânia-GO, Brasil Central: elementos para o cuidado a grupos sociais vulneráveis," under the coordination of Faculdade de Enfermagem - Universidade Federal de Goiás. 
For the investigation of oral-health-related aspects, the study population was composed of a convenience sample of 120 individuals. Inclusion criteria were: being at the institution during the period of data collection (three days of the week alternating between September 2014 and August 2015) and aging 18 years or older. Those who were under the influence of substances that put the researchers' integrity at risk were excluded.

Prior to the completion of the survey, a pilot study was developed. Data was collected by an interview conducted at the Casa de Passagem and by oral clinical examination. Interviewers (20 students and healthcare professionals) were previously trained. The instrument featured questions related to sociodemographic characteristics of individuals and a block of questions on the impact of oral condition on the daily performance of activities, measured by the Oral Impact on Daily Performance (OIDP) ${ }^{15}$.

For the OIDP, individuals were questioned in relation to the last six months about a problem with their oral health that caused difficulties or detriments in the following performances: eating; talking; brushing teeth; sleeping and relaxing; smiling or speaking without shame; maintaining a balanced emotional state without getting nervous or angry; performing the work or main activity; and having contact with people. Following the methodology of the national oral health research (Projeto SBBrasil 2010 [2010 SBBrasil Project]) ${ }^{16}$, the possible responses to each of the eight items were: yes; no; do not know; or did not answer.

Sociodemographic variables and their categories were: age; sex; self-reported skin color/race; common-law relationship: lives with a partner (yes, no); education level, measured in years of study: high (nine or over) and low (up to eight); period living in the streets; and length of stay at the institution. The classification of skin color/race was based on the categories of the Brazilian Institute of Geography and Statistics (IBGE) ${ }^{17}$ : whites, blacks, pardos, yellows, and indigenous. For statistical analysis, these categories were dichotomized (white, non-white).

The following dental conditions were evaluated: dental caries and the use and need of prostheses in both arches. Caries was evaluated by the DMFT index (decayed, missing, filled teeth), using the criteria of the World Health Organization (WHO) ${ }^{18}$. For the assessment of the use and the need for dental prosthesis the following types of prostheses were considered: fixed denture, removable partial denture, and complete denture. The prevalence was determined by the presence or need for at least one type of dental prosthesis in each of the upper and lower arches.

Clinical data were collected by an examiner (dental surgeon) who was trained before conducting the survey. For estimation of the intra-examiner agreement, Kappa statistic was used, with values of 0.97 (almost perfect agreement) for caries and 1.0 (100\% agreement) for the need and use of prosthesis. The periodontal probe, recommended by the WHO, and a mouth mirror were used for oral examination.

Statistical analysis initially comprised the descriptive analysis of the variables. The dependent variable was the oral health impact on quality of life (OIDP) and independent variables were sociodemographic characteristics and the dental condition of individuals. Initially, the prevalence of each item of the OIDP was estimated considering the answers: yes (presence) and no (absence). To estimate the prevalence of total impact (OIDP), the presence of at least one item with impact was considered, being dichotomized in "yes" (sum of the eight items totaling a value equal to or more than one) and "no" (sum of the eight items totaling zero).

Next, bivariate analyses were performed to verify the association between impact and each of the other sociodemographic and clinical variables, using the Pearson's Chi-square and Fisher's exact tests. For the analysis of each of the items of the OIPD separately, the presence or absence of impact were considered. Since the prevalence of total impact was low, we decided to categorize it into two levels, based on the median: low impact (OIDP from 0 to 3 ) and high impact (OIDP from 4 to 8). 
The clinical variable that was associated with the impact (total OIDP), with $\mathrm{p}<0.05$ significance level, was analyzed by a Poisson regression with robust variance model. The selection of possible confounding variables in each model was based on the value of $p<$ 0.20 obtained in the bivariate analyses. We kept in the final model only those with $\mathrm{p}<0.05$ significance. Demographic variables (age and sex) were inserted into the adjusted model regardless of the $p$ value. Estimations were performed using the Statistical Package for the Social Sciences (SPSS) program for Windows, version 17.0.

The project was approved by the Research Ethics Committee of the Universidade Federal de Goiás (Protocol 045/2013). Individuals invited to participate were guided on the research and those who agreed to participate signed an informed consent form.

\section{RESULTS}

Of 120 individuals invited to participate in the study, 116 have accepted (response rate $=96.7 \%$ ). Sociodemographic characteristics of the participants are presented in Table 1 . The sample was predominantly composed of men (84.5\%) and the age ranged from 18 to 77 years (mean $=38.7)$. As for the self-reported skin color/race, more than half were pardos (51.7\%). Most did not live with a partner (82.7\%), had low education level (65.5\%), and were more than 14 days in the institution (56.9\%). Approximately $40 \%$ of individuals reported to be less than a year living in the streets, and $56.9 \%$ were in the institution for at least 14 days.

Table 1. Sociodemographic characteristics and oral condition of homeless people. Goiânia, state of Goiás, Brazil. $(n=116)$

\begin{tabular}{|c|c|c|c|}
\hline Variable & & $\mathbf{n}$ & $\%$ \\
\hline \multirow[t]{2}{*}{ Age $(n=115)$} & 18 to 35 years & 56 & 48.3 \\
\hline & 36 to 77 years & 59 & 50.8 \\
\hline \multirow[t]{2}{*}{ Sex } & Male & 98 & 84.5 \\
\hline & Female & 18 & 15.5 \\
\hline \multirow[t]{5}{*}{ Skin color $(n=113)$} & White & 26 & 22.4 \\
\hline & Black & 21 & 18.1 \\
\hline & Mixed-race & 60 & 51.7 \\
\hline & Yellow & 2 & 1.7 \\
\hline & Indigenous & 4 & 3.4 \\
\hline \multirow[t]{2}{*}{ Lives with a partner $(\mathrm{n}=113)$} & Yes & 17 & 14.7 \\
\hline & No & 96 & 82.7 \\
\hline \multirow[t]{2}{*}{ Education level } & High (9 years or over) & 36 & 31.0 \\
\hline & Low (up to 8 years of study) & 76 & 65.6 \\
\hline \multirow[t]{2}{*}{ Time living on the street $(\mathrm{n}=78)$} & Up to 1 year & 46 & 39.7 \\
\hline & More than 1 year & 32 & 27.5 \\
\hline \multirow[t]{2}{*}{ Length of stay in the institution $(n=113)$} & 1 to 13 days & 47 & 40.5 \\
\hline & 14 days or over & 66 & 56.9 \\
\hline \multirow[t]{2}{*}{ DMFT } & Low & 49 & 42.2 \\
\hline & High & 67 & 57.8 \\
\hline \multirow[t]{2}{*}{ Decayed teeth } & No & 28 & 24.1 \\
\hline & Yes & 88 & 75.9 \\
\hline \multirow[t]{2}{*}{ Missing teeth } & No & 10 & 8.6 \\
\hline & Yes & 106 & 91.4 \\
\hline \multirow[t]{2}{*}{ Using upper prosthesis } & No & 100 & 86.2 \\
\hline & Yes & 16 & 13.8 \\
\hline \multirow[t]{2}{*}{ Using lower prosthesis } & No & 113 & 97.4 \\
\hline & Yes & 3 & 2.6 \\
\hline \multirow[t]{2}{*}{ Need for upper prosthesis } & No & 36 & 31.0 \\
\hline & Yes & 80 & 69.0 \\
\hline \multirow[t]{2}{*}{ Need for lower prosthesis } & No & 27 & 23.3 \\
\hline & Yes & 89 & 76.7 \\
\hline
\end{tabular}


Regarding the dental condition, only two individuals had no caries (1.7\%). The mean DMFT was 14.41 ( $\mathrm{SD}=9.14$ ), composed by $59.8 \%$ of missing, $29.4 \%$ decayed, and $10.9 \%$ filled teeth. Most of the individuals had high DMFT (58.0\%) and teeth with untreated caries (75.9\%) (Table 1). The use of prosthesis was identified in $13.8 \%$ of the individuals in the upper arch, and $2.6 \%$ in the lower arch. The need for prosthesis was found in $69.0 \%$ and $76.7 \%$ of the sample in the upper and lower arches, respectively.

In Table 2 we present the prevalence of the oral condition impact on quality of life, according to the OIDP index. Most individuals (81.9\%) reported at least one performance or daily activity affected by oral problems over the last six months prior the survey. The performances "difficulty in eating" (59.5\%) and "being ashamed to smile or talk" (59.5\%) were the most affected, followed by the performance "feeling uncomfortable when brushing my teeth" (55.2\%). The performance with lower prevalence of impact was "the teeth hinder my work" (38.8\%).

In Tables 3 and 4 we present the results of bivariate analyses of the association between prevalence of impact (OIDP) and each of the sociodemographic and clinical variables. We found no significant differences concerning sociodemographic characteristics (Table 3).

Table 2. Prevalence of oral impact on daily performance (OIDP) of homeless people. Goiânia, state of Goiás, Brazil. $(\mathrm{n}=116)$

\begin{tabular}{|c|c|c|c|c|c|c|}
\hline \multirow{2}{*}{ Items } & \multicolumn{2}{|c|}{ No } & \multicolumn{2}{|c|}{ Yes } & \multicolumn{2}{|c|}{ Did not answer } \\
\hline & $\mathbf{n}$ & $\%$ & $\mathbf{n}$ & $\%$ & $\mathbf{n}$ & $\%$ \\
\hline 1 - Difficulty in eating because of the teeth & 44 & 37.9 & 69 & 59.5 & 3 & 2.6 \\
\hline 2 - Feeling uncomfortable when brushing your teeth & 49 & 42.2 & 64 & 55.2 & 3 & 2.6 \\
\hline 3 - Teeth make you nervous or irritated & 53 & 45.7 & 58 & 50.0 & 5 & 4.3 \\
\hline 4 - Having no fun anymore because of the teeth & 65 & 56.0 & 47 & 40.6 & 4 & 3.4 \\
\hline 5 - Difficulty in speaking because of the teeth & 62 & 53.4 & 51 & 44.0 & 3 & 2.6 \\
\hline 6 - Being ashamed and do not smile anymore & 44 & 37.9 & 69 & 59.5 & 3 & 2.6 \\
\hline 7 - The teeth hinder my work & 68 & 58.6 & 45 & 38.8 & 3 & 2.6 \\
\hline 8 - Slept poorly because of the teeth & 65 & 56.0 & 48 & 41.4 & 3 & 2.6 \\
\hline Total OIDP* & 18 & 15.5 & 95 & 81.9 & 3 & 2.6 \\
\hline
\end{tabular}

* Sum of the 8 items.

Table 3. Association between sociodemographic variables and oral impact on the daily performance (OIDP) of homeless people. Goiânia, state of Goiás, Brazil. $(n=116)$

\begin{tabular}{|c|c|c|c|c|c|}
\hline \multirow{3}{*}{ Variable } & \multicolumn{4}{|c|}{ Impact (OIDP) } & \multirow{3}{*}{$\mathbf{p}^{*}$} \\
\hline & \multicolumn{2}{|c|}{ High } & \multicolumn{2}{|c|}{ Low } & \\
\hline & n & $\%$ & $n$ & $\%$ & \\
\hline Age (years) & & & & & 0.343 \\
\hline $18-35$ & 28 & 45.9 & 28 & 54.9 & \\
\hline $36-77$ & 33 & 54.1 & 23 & 45.1 & \\
\hline Sex & & & & & 0.508 \\
\hline Male & 50 & 82.0 & 45 & 86.5 & \\
\hline Female & 11 & 18.0 & 7 & 13.5 & \\
\hline Skin color & & & & & 0.950 \\
\hline White & 14 & 23.0 & 11 & 22.4 & \\
\hline Non-white & 47 & 77.0 & 38 & 77.6 & \\
\hline Lives with a partner & & & & & 0.761 \\
\hline Yes & 10 & 16.4 & 7 & 14.3 & \\
\hline No & 51 & 83.6 & 42 & 85.7 & \\
\hline Education level & & & & & 0.913 \\
\hline High & 19 & 31.7 & 16 & 32.7 & \\
\hline Low & 41 & 68.3 & 33 & 67.3 & \\
\hline Time in the institution (days) & & & & & 0.172 \\
\hline 1 to 13 & 22 & 36.1 & 24 & 49.0 & \\
\hline 14 or over & 39 & 63.9 & 25 & 51.0 & \\
\hline Time living on the street (years) & & & & & 0.174 \\
\hline Up to 1 & 25 & 53.2 & 20 & 69.0 & \\
\hline More than 1 year & 22 & 46.8 & 9 & 31.0 & \\
\hline
\end{tabular}

* Pearson's Chi-square test. 
As for the clinical variables (Table 4), we found significant differences $(p<0.05)$ between the following variables and OIDP items: DMFT and item 8 (slept poorly); need for upper prosthesis and all OIDP items, except item 4 (have no fun anymore) and item 5 (difficulty in speaking). The only clinical variable associated with the prevalence of total impact (high OIDP) was need for upper prosthesis. We observed a higher proportion of high impact in individuals who require this type of rehabilitation treatment $(p=0.005)$.

In Table 5 we present the results of the Poisson regression analysis to test the association between prevalence of impact (high OIDP) and need for upper prosthesis. In the unadjusted model, only the "need for upper prosthesis" variable was associated with the outcome $(p=0.015)$. These variables remained associated even after adjustment for sex, age, and time in the institution. Individuals without need for upper prosthesis had prevalence of high impact on daily performance $55 \%$ lower than those in need of this type of prosthesis $(\mathrm{p}=0.018)$.

Table 4. Association between oral impact on the daily performance (OIDP) and clinical variables of homeless people. Goiânia, state of Goiás, Brazil. $(\mathrm{n}=116)$

\begin{tabular}{|c|c|c|c|c|c|c|c|c|c|}
\hline \multirow{2}{*}{ Variable } & \multicolumn{9}{|c|}{ Presence of impact (OIDP) - n (\%) } \\
\hline & Item 1 & Item 2 & Item 3 & Item 4 & Item 5 & Item 6 & Item 7 & Item 8 & High impact \\
\hline \multicolumn{10}{|l|}{ DMFT } \\
\hline Low & $25(51.0)$ & $23(46.9)$ & $23(46.9)$ & $16(32.7)$ & $17(34.7)$ & $30(61.2)$ & 15 (30.6) & 15 (30.6) & $23(46.9)$ \\
\hline High & $44(68.8)$ & $41(64.1)$ & $35(56.5)$ & $31(49.2)$ & $34(53.1)$ & $39(60.9)$ & $30(46.9)$ & $33(51.6)^{\mathrm{a}}$ & $38(59.4)$ \\
\hline \multicolumn{10}{|c|}{ Decayed teeth } \\
\hline No & $13(48.1)$ & $15(55.6)$ & $12(46.2)$ & $10(37.0)$ & $12(44.4)$ & $13(48.1)$ & $8(29.6)$ & 7 (25.9) & $13(48.1)$ \\
\hline Yes & $56(65.1)$ & $49(57.0)$ & $46(54.1)$ & $37(43.5)$ & $39(45.3)$ & $56(65.1)$ & $37(43.0)$ & $41(47.7)$ & $48(55.8)$ \\
\hline \multicolumn{10}{|c|}{ Missing teeth } \\
\hline No & $65(62.5)$ & $58(55.8)$ & $54(52.4)$ & $43(41.7)$ & $45(43.3)$ & $65(62.5)$ & $42(40.4)$ & $46(44.2)$ & $57(54.8)$ \\
\hline Yes & $4(44.4)$ & $6(66.7)$ & $4(50.0)$ & $4(44.4)$ & $6(66.7)$ & $4(44.4)$ & $3(33.3)$ & $2(22.2)$ & $4(44.4)$ \\
\hline \multicolumn{10}{|c|}{ Using upper prosthesis } \\
\hline No & $58(59.2)$ & $54(55.1)$ & $50(52.1)$ & $39(40.2)$ & $42(42.9)$ & $59(60.2)$ & $38(38.8)$ & $40(40.8)$ & $52(53.1)$ \\
\hline Yes & $11(73.3)$ & $10(66.7)$ & $8(53.3)$ & $8(53.3)$ & $9(60.0)$ & $10(66.7)$ & $7(46.7)$ & $8(53.3)$ & $9(60.0)$ \\
\hline \multicolumn{10}{|c|}{ Using lower prosthesis } \\
\hline No & $67(60.9)$ & $62(56.4)$ & $57(52.8)$ & $46(42.2)$ & $50(45.5)$ & $67(60.9)$ & $44(40.0)$ & $47(42.7)$ & $60(54.5)$ \\
\hline Yes & $2(66.7)$ & $2(66.7)$ & $1(33.3)$ & $1(33.3)$ & $1(33.3)$ & $2(66.7)$ & $1(33.3)$ & $1(33.3)$ & $1(33.3)$ \\
\hline \multicolumn{10}{|c|}{ Need for upper prosthesis } \\
\hline No & $13(37.1)$ & $14(40.0)$ & $12(34.3)$ & $10(29.4)$ & $11(31.4)$ & $16(45.7)$ & $7(20.0)$ & $8(22.9)$ & $12(34.3)$ \\
\hline Yes & $56(71.8)^{a}$ & $50(64.1)^{c}$ & $46(60.5)^{c}$ & $37(47.4)$ & $40(51.3)$ & $53(67.9)^{c}$ & $38(48.7)^{\mathrm{b}}$ & $40(51.3)^{b}$ & $49(62.8)^{b}$ \\
\hline \multicolumn{10}{|c|}{ Need for lower prosthesis } \\
\hline No & $13(48.1)$ & $16(59.3)$ & $14(51.9)$ & $10(38.5)$ & $8(29.6)$ & $16(59.3)$ & $10(37.0)$ & $11(40.7)$ & $12(44.4)$ \\
\hline Yes & $56(65.1)$ & $48(55.8)$ & $44(52.4)$ & $37(43.0)$ & $43(50.0)$ & $53(61.6)$ & $35(40.7)$ & $37(43.0)$ & $49(57.0)$ \\
\hline
\end{tabular}

Pearson's Chi-square test

a $\mathrm{p}<0.001$

${ }^{\mathrm{b}} \mathrm{p}<0.01$

c $p<0.05$

Table 5. Poisson regression results of the association between high oral impact on the daily performance of homeless people and the need for upper prosthesis variable. Goiânia, state of Goiás, Brazil. $(n=110)$

\begin{tabular}{|c|c|c|c|c|}
\hline \multirow{2}{*}{ Independent variable } & \multicolumn{2}{|c|}{$\begin{array}{r}\text { Unadjusted } \\
\end{array}$} & \multicolumn{2}{|c|}{ Adjusted } \\
\hline & PR $(95 \% \mathrm{Cl})$ & $\mathbf{p}$ & PR $(95 \% \mathrm{Cl})$ & $\mathbf{p}$ \\
\hline \multicolumn{5}{|c|}{ Need for upper prosthesis } \\
\hline No & $0.55(0.34-0.89)$ & \multirow{2}{*}{0.015} & $0.55(0.34-0.90)$ & \multirow{2}{*}{0.018} \\
\hline Yes & 1 & & 1 & \\
\hline \multicolumn{5}{|l|}{ Age (years) } \\
\hline 18-35 & $0.85(0.60-1.19)$ & \multirow{2}{*}{0.345} & $0.97(0.70-1.34)$ & \multirow{2}{*}{0.849} \\
\hline $36-77$ & 1 & & 1 & \\
\hline \multicolumn{5}{|l|}{ Sex } \\
\hline Male & $0.86(0.57-1.30)$ & \multirow{2}{*}{0.480} & $0.82(0.57-1.18)$ & \multirow{2}{*}{0.28} \\
\hline Female & 1 & & 1 & \\
\hline \multicolumn{5}{|c|}{ Time in the institution (days) } \\
\hline 1 to 13 & $0.78(0.55-1.12)$ & \multirow{2}{*}{0.187} & $0.84(0.59-1.21)$ & \multirow{2}{*}{0.3} \\
\hline 14 or over & 1 & & 1 & \\
\hline
\end{tabular}




\section{DISCUSSION}

This is the first study to assess factors associated with the impact of oral health on homeless people in Brazil. The prevalence of negative impact was high in the studied group (81.9\%). Among the analyzed clinical variables, only the need for upper prosthesis was associated with the outcome after adjustment for individuals' sociodemographic characteristics.

Data on the Brazilian population obtained from Pesquisa Nacional de Saúde Bucal [National Survey of Oral Health], held in 2010, show lower prevalence of impact (OIDP) in adults and older people ( $54.9 \%$ and $45.3 \%$, respectively) ${ }^{16}$. Considering the precarious living conditions and health care provided by the public services to the homeless population, this result was expected.

In our study, the lack of association of the negative impact with other clinical variables (dental caries, use of prosthesis, and need for lower prosthesis) may be due to the characteristics of the studied group. The homeless situation constantly generates highly-complexity challenges and demands struggle for survival, which compromise the health and other aspects of the lives of individuals, and oral health is just one of them ${ }^{19}$. Thus, unlike what is observed in the overall population, the precarious oral condition of these individuals, such as high percentage of untreated carious teeth and dental loss, may not considerably affect their daily performance. Similarly, the individual sociodemographic factors we studied did not influence on the prevalence of impact.

Tooth loss in the upper arch and no prosthetic replacement, on the other hand, compromise the appearance and quality of life of individuals, since teeth are more exposed in this $\operatorname{arch}^{20}$. Although living on the streets, the need for having a good physical appearance, according to conventional aesthetic patterns, seems to be preserved. In addition to appearance, using no prosthesis in the upper arch can affect chewing in a more scathing way than in the lower arch. Due to the difficulty of adjustment of lower dentures, abandoning its use and being used to this situation are frequent, even among the general population.

Previous studies conducted on homeless people from other countries show similar results, in which the clinical variables associated with the negative impact were the number of dental treatments required ${ }^{8}$ and tooth $\operatorname{loss}^{12}$. In Hong Kong, however, sociodemographic factors were associated with the impact ${ }^{10}$.

The daily performances most affected in our study were "difficult in eating" and "being ashamed or do not smile anymore," as well as in the Brazilian population of adults and older people ${ }^{16}$, and reinforce the need for upper prosthesis in the perception of impact in the studied group.

Comparisons with results of previous studies are limited, considering the lack of studies based on the same methodology about homeless people. The only study found in the literature on the quality of life related to oral health of homeless people in Brazil showed prevalence of impact close to our study in men attended by temporary shelter in a municipality of Minas Gerais $(78.0 \%)^{14}$. In such study ${ }^{14}$, the instrument used to assess the quality of life was the Oral Health Impact Profile (OHIP-14) and the most affected dimensions were: psychological discomfort (70\% felt embarrassed and tense) and psychological incapacity (54\%); clinical conditions and other factors associated with the impact were not investigated.

Studies carried out with homeless population from other countries report prevalence close to our study in England $(91 \%)^{12}$, Australia $(80.4 \%)^{8}$, and Hong Kong $(88 \%)^{10}$. In the United Kingdom, the most frequent impacts were: toothache, discomfort, and chewing difficulty ${ }^{12,13}$. As in our study, samples were obtained from institutions that temporarily housed individuals, but using the OHIP-14.

Some limitations should be considered in our study. The size of the study population is small and the results represent homeless people attended by an institution, and cannot be 
extended to the homeless population of the entire municipality studied. On the other hand, epidemiological surveys on oral health based on the methodological guidelines generally applied in population surveys is unfeasible due to the characteristics of the study population. This difficulty has been observed also in other countries.

Hence, to date, the evidence about the impact of oral health on the quality of life of homeless people is based on temporarily-institutionalized population groups. Considering that the institutions can provide better living conditions to individuals, even if temporarily, and that data were collected during their stay in these places, the perceived impact is expected to be less severe.

Therefore, more studies are needed to broadly understand how oral condition influences on the quality of life of homeless people. Further research should also include individuals who are not attended by institutions housing homeless people, as well as qualitative methods of research to deepen aspects related to the meaning of the oral health in the context of living on the streets.

We conclude that the prevalence of the impact of oral condition on the performance of daily activities of homeless people was high, especially for individuals who require upper prosthesis, regardless of sociodemographic characteristics.

These results strengthen the importance of improving the health care provided to the homeless population and meeting the oral health needs perceived by this extremely disadvantageous group ${ }^{5}$, contributing to a better quality of life and the restoration of their dignity $^{13,21,22}$. Facilitating the access to treatment and training oral health professionals to provide proper care to these patients are crucial measures ${ }^{23}$.

Whereas the need for prosthesis was the main factor related to the negative impact on the daily performance of homeless people of our study, dental care must go beyond tooth extractions and pain relief, and include dental prosthetic rehabilitation ${ }^{5}$. In addition to existing needs perceived by these people, broader strategies for promoting health care may contribute to the maintenance of oral health in the overall population.

\section{REFERENCES}

1. Petersen PE. Strengthening of oral health systems: oral health through primary health care. Med Princ Pract. 2014;23 Suppl 1:3-9. https://doi.org/10.1159/000356937

2. Cushing AM, Sheiham A, Maizels J. Developing socio-dental indicators: the social impact of dental disease. Community Dent Health. 1986;3(1):3-17.

3. Cascaes AM, Leão AT, Locker D. Impacto das condições de saúde bucal na qualidade de vida. In: Antunes JLF, Peres MA, organizadores. Epidemiologia da saúde bucal. 2.ed. São Paulo: Editora Santos; 2013. p.437-58. (Fundamentos da Odontologia).

4. Ministério do Desenvolvimento Social e de Combate à Fome (BR). Pesquisa Nacional sobre a População em Situação de Rua. Brasília (DF); 2008.

5. Ministério da Saúde (BR), Secretaria de Atenção à Saúde, Departamento de Atenção Básica. Manual sobre o cuidado à saúde junto a população em situação de rua. Brasília (DF); 2012 [cited 2018 Apr 21]. (Série A. Normas e Manuais Técnicos0. Available from: http://189.28.128.100/dab/docs/publicacoes/geral/manual_cuidado_populalcao_rua.pdf

6. Ministério da Saúde (BR), Secretaria de Gestão Estratégica e Participativa, Departamento de Apoio à Gestão Participativa. Saúde da população em situação de rua: um direito humano. Brasília (DF); 2014 [cited 2018 Apr 21]. Available from: http://bvsms.saude.gov.br/bvs/ publicacoes/saude_populacao_situacao_rua.pdf

7. Aguiar MM, Iriart JAB. Significados e práticas de saúde e doença entre a população em situação de rua em Salvador, Bahia, Brasil. Cad Saude Publica. 2012;28(1):115-24. https://doi.org/10.1590/S0102-311X2012000100012

8. Ford PJ, Cramb S, Farah CS. Oral health impacts and quality of life in an urban homeless population. Aust Dent J. 2014;59(2):234-9. https://doi.org/10.1111/adj.12167 
9. Conte $M$, Broder $\mathrm{HL}$, Jenkins $\mathrm{G}$, Reed R, Janal MN. Oral health, related behaviors and oral health impacts among homeless adults. J Public Health Dent. 2006;66(4):276-8. https://doi.org/10.1111/j.1752-7325.2006.tb04082.x

10. Luo Y, McGrath C. Oral health and its impact on the life quality of homeless people in Hong Kong. Community Dent Health. 2008;25(3):137-42. https://doi.org/10.1922/CDH_2157Lou06

11. Coles E, Chan K, Collins J, Humphris GM, Richards D, Williams B, et al. Decayed and missing teeth and oral-health-related factors: predicting depression in homeless people. J Psychosom Res. 2011;71(2):108-12. https://doi.org/10.1016/j.jpsychores.2011.01.004

12. Daly B, Newton $T$, Batchelor $\mathrm{P}$, Jones $\mathrm{K}$. Oral health care needs and oral health-related quality of life (OHIP-14) in homeless people. Community Dent Oral Epidemiol. 2010;38(2):136-44. https://doi.org/10.1111/j.1600-0528.2009.00516.x

13. Collins J, Freeman R. Homeless in North and West Belfast: an oral health needs assessment. $\mathrm{Br}$ Dent J. 2007;202(12):E31. https://doi.org/10.1038/bdj.2007.473

14. Segatto TD, Araújo LB, Rodrigues RPCB. Percepção de ex-moradores de rua sobre sua qualidade de vida. Rev Fac Odontol Lins. 2016;26(2):25-34. https://doi.org/10.15600/2238-1236/fol.v26n2p25-34

15. Adulyanon S, Vourapukjaru J, Sheiham A. Oral impacts affecting daily performance in a low dental disease Thai population. Community Dent Oral Epidemiol. 1996;24(6):385-9. https://doi.org/10.1111/j.1600-0528.1996.tb00884.x

16. Ministério da Saúde (BR), Secretaria de Atenção à Saúde, Secretaria de Vigilância em Saúde. Projeto SB Brasil 2010: Pesquisa Nacional de Saúde Bucal: resultados principais. Brasília (DF); 2012 [cited 2018 Apr 21]. Available from: http://189.28.128.100/dab/docs/portaldab/ publicacoes/pesquisa_saude_bucal.pdf

17. Instituto Brasileiro de Geografia e Estatística. Censo Brasileiro 2010. Rio de Janeiro: IBGE; 2010.

18. World Health Organization. Oral health surveys: basic methods. 4.ed. Geneva: WHO; 1997 [cited 2018 Apr 21]. Available from: http://apps.who.int/iris/bitstream/ handle/10665/41905/9241544937.pdf?sequence=1 \&isAllowed=y

19. Silveira JLGC, Stanke R. Condição e representações da saúde bucal entre os sem-teto do município de Blumenau - Santa Catarina. Cienc Cogn. 2008 [cited 2018 Apr 21];13(1):2-11. Available from: http://pepsic.bvsalud.org/pdf/cc/v13n1/v13n1a02.pdf

20. AL-Omiri MK, Karasneh JA, Lynch E, Lamey PJ, Clifford TJ. Impacts of missing upper anterior teeth on daily living. Int Dent J. 2009;59(3):127-32. https://doi.org/10.1922/IDJ_1994ALOmiri06

21. De Palma P, Nordenram G. The perceptions of homeless people in Stockholm concerning oral health and consequences of dental treatment: a qualitative study. Spec Care Dentist. 2005;25(6):289-95. https://doi.org/10.1111/j.1754-4505.2005.tb01403.x

22. Gibson G, Reifenstahl EF, Wehler CJ, Rich SE, Kressin NR, King TB, et al. Dental treatment improves self-rated oral health in homeless veterans: a brief communication. J Public Health Dent. 2008;68(2):111-5. https://doi.org/10.1111/j.1752-7325.2007.00081.x

23. DiMarco MA, Ludington SM, Menke EM. Access to and utilization of oral health care by homeless children/families. J Health Care Poor Underserved. 2010;21(2 Suppl):67-81. https://doi.org/10.1353/hpu.0.0277

Funding: United Nations Office on Drugs and Crime (UNODC - Agreement Letter 100/2013).

Authors' Contribution: Design and planning of the study: JACL, MAM, JBS, MCMF. Data collection: JACL. Data analysis and interpretation, and preparation of the unpublished study: JACL, MCMF. All authors critically reviewed the unpublished study and approved the final version to be published.

Conflict of Interest: The authors declare no conflict of interest. 